Article

\title{
Sustainable Development of Rural Areas in the EU and China: A Common Strategy for Architectural Design, Research Practice and Decision-Making
}

\author{
Tiziano Cattaneo ${ }^{1, *}$, Emanuele Giorgi ${ }^{1,3}$, Minqing $\mathrm{Ni}^{2}$ and Giorgio Davide Manzoni ${ }^{1}$ \\ 1 China Laboratory for Architecture and Urban Studies, Department of Civil Engineering and Architecture, \\ University of Pavia, Via Ferrata, 1-27100 Pavia, Italy; emanuele.giorgi@unipv.it (E.G.); \\ giorgiodavide.manzoni@unipv.it (G.D.M.) \\ 2 College of Design and Innovation, Tongji University, No.281 Fuxin Road, Yangpu District, \\ Shanghai 200092, China; niminqing@tongji.edu.cn \\ 3 Escuela de Arquitectura y Diseño, División de Ingeniería y Arquitectura, Tecnológico de Monterrey, \\ Campus León, Av. Eugenio Garza Sada S/N, Cerro Gordo, León 37190, Mexico \\ * Correspondence: tiziano.cattaneo@unipv.it; Tel.: +39-347-080-3920 \\ Academic Editor: Adrian Pitts \\ Received: 31 July 2016; Accepted: 11 October 2016; Published: 18 October 2016
}

\begin{abstract}
This paper describes the results of a research project to develop a set of goals and strategies aimed at policymakers, stakeholders, researchers, designers and/or some other groups of citizens' communities whose development actions are undertaken in a specific rural context. The aim of the project was to move beyond the knowledge of the articulated architectural and social evolution of the rural areas in both the EU and China, looking at the local and global challenges, at the need for continuous adaptation and at the experiences of resilience that the countryside faces today. The paper shows, through two-pronged methods, such as semantic analysis and a meta-project design, that a common strategy can be set to support actions for the development of rural areas both in China and the EU. In doing so, this study has defined a strategy system tool that is a type of interactive and generative key-checklist that can be used by stakeholders in specific contexts, becoming a reading tool, a set of design guidelines or a decision facilitator support system. The results achieved have been tested through design application in two meta-projects that confirm the validity of the whole research framework with the aim of promoting a sustainable development and enhancement of places and rural communities.
\end{abstract}

Keywords: architectural design; rural-urban development; Europe and China; strategy tool; sustainable design; meta-projects

\section{Introduction}

The crisis of rural areas is a global problem. From north to south and from west to east across the world, there are similar imbalances. Although caused by different economic, social and political conditions, the same crisis impacts occur in rural regions, i.e., depopulation, ageing of the population, abandonment, decay of small town centers, difficulty in keeping existing businesses and/or in launching new start-ups, the detriment of biodiversity, pollution, a lack of adequate infrastructures, deficiency of services for tourism and a shortage of job opportunities for the population, just to list some of those problems [1].

There are possible solutions to each of these problems and different paths to follow, depending on the potential of each region, on its physical characteristics, but also on its social and economic policies.

Over the last few decades, these solutions have been closely examined by certain projects and initiatives, which has been of great interest to the authorities both in the EU [2,3] and China [4]. 
These solutions are being discussed by institutions at conventions, debates or during legislative actions at international, national, regional and municipal levels; they are being discussed by the populations organized into associations and movements, action groups and eco villages; they are being discussed by the European Union, which for years has been introducing intervention strategies and community policies, funding experimental programs, as well as establishing cooperation networks and pilot projects that provide training and information in order to implement the activities in rural regions [5]; lastly, they are being discussed by designers, planners and architects, namely experts in the area, those who come up with possible scenarios once they have gathered all of the necessary information and identified the various ways to learn about and understand the region.

Having said that, we believe that enhancing rural architecture, small towns, farmsteads and ancient relics is one of the main components in the regeneration of the countryside. It is a strategy with a positive outcome, especially if it has been supported simultaneously by the possibility of creating more business (also working from its architectural heritage), but which nevertheless is planned taking into account the improvement of the perceived aesthetic structure of the countryside. Therefore, in this development process for business in the region, there must also be an increase in the environmental quality and in the infrastructures that allow people to use the environment. Furthermore, the development of small- and medium-sized enterprises represents a possible opening strategy, but in this case, as well, only if it allows the possibility at the same time of reusing the existing building heritage or at least respects its presence as a unique value for a region. In the meantime, small- and medium-sized enterprises should be supported by specific services, such as access to information and communication technologies, and they must also have new types of sustainable infrastructures for the environment that allow businesses to establish themselves in a region and to promote new initiatives. The protection of biodiversity, as well as new models of organic and biodynamic farming can translate into opportunities to diversify the range of services towards other economic sectors, as well, such as tourism [6].

To this end, the research question is: What strategies can be used to foster the development of a rural region?

With the aim of advancing a common working hypothesis on both the EU and China, we have defined, as a first step, a precise application domain. It is necessary to point out that understanding or explaining China's issues using Western development experience and principles is impossible mainly because there is a societal development gap between China and EU countries, and differences in the social system make comparative studies theoretical research isolated from reality [7]. Having said that, despite the fact that China and the EU are in different stages of development, those kinds of rural areas will also be the foundation upon which future communities will be built [8]. Therefore, we believe that now, all of the economic, social and political ingredients are available to develop new knowledge, which can be combined to produce the best results between European technology and China's organizational implementation skills.

Policymakers from the European Union (EU) and P.R. China are stepping up efforts to achieve a strong and beneficial partnership on sustainable urban development. The main step forward in the relationship between China and the EU is the Joint Declaration on the EU-China Partnership on Urbanisation, signed by European Commission President José Manuel Barroso and Li Keqiang, Vice Premier of the People's Republic of China, on 3 May 2012. The Partnership is aimed at tackling challenges together through cooperative efforts between stakeholders at all appropriate levels, including national, regional and local levels. The Partnership highlights, among other things, the following subjects: (1) strategies and policies relevant to the development of urbanization; (2) the spatial distribution of urbanization; (3) sustainable development of urban industrial economy; (4) the urban public services system; (5) urban infrastructure investment and financing mechanisms; (6) the urban housing supply system and patterns; (7) urban energy supply and demand management; (8) urban mobility, public transport and smart transport; (9) urban green buildings; (10) urban ecological protection, environmental protection and treatment; (11) protection of urban historical and cultural 
features and the formation of the urban landscape; (12) urban governance; (13) urban-rural integrated development; and (14) exchanges and discussions, as well as personnel training in urbanization development [9].

Animated by those principles, we were inspired to deepen the understanding of Point 13 of the Joint Declaration, urban-rural integrated development, focusing on China's mega-city suburbs, which include both small towns and rural areas, and the EU's peripheral territory, which includes both small villages and rural areas.

\section{Methodology and Results}

European and Chinese rural areas are different realities, whose crisis is often dictated by different reasons, but they may, however, have the same strategy system tool for their development.

The results achieved with this research bring into contact two strongly identified territories that are in their own phase of development. A unique strategy system tool (which can be used as a tool kit or a decision-maker tool) has been built. The strategy system tool is a type of interactive checklist for design, research practice and decision-making.

The purpose was to create a common ground for advanced multiple-criteria decision-making (MCDM) with the aim of discovering innovations and alternative design hypotheses that may cope with and/or offer working programs on the ongoing phenomena in the rural areas. Outputs that the strategy system tool can provide are:

- Comparative interactions between goals and strategies for the development of rural areas.

- Design tactics based on goal assumptions in a specific context.

- The consequences of different decision alternatives in that specific context.

\subsection{Methodology}

The methodology adopted for this research could be described as a two-phase research design that involves more strategies in a sequence of distinct phases. Linda Groat and David Wang's book on architectural research methods [10] provides a definition and explanation of the advantage and disadvantage of this research strategy. The advantage of such an approach is that the particular procedures and standards associated with each strategy can be presented fully and distinctly. A ossible disadvantage is the potential for a perceived lack of connection or coherence if the strategies are not conceptually well linked. Aware of this risk, we conceived of a methodology in two complementary phases as follows:

First work package and related tasks:

- Knowledge preparation: definition of the application domain;

- Data collection and definition of the goals and strategies (taken from a wide range of documents and materials from both China and the EU) using widespread technologies and software for semantic analysis;

- Creation of a strategy system tool graphically represented by a semantic diagram.

Second work package and related tasks:

- Application of the strategy system tool in two contexts (one in the EU (Italy) and one in China (Fujian)) specifying the main aims to achieve in those specific contexts;

- Envisioning rural architectural development in two selected rural areas through meta-projects designed based on the tactics deduced from the strategy system tool. The two meta-projects show the validity of the whole approach;

- Revision and adaptation of the results of the strategy system tool. 
This methodology is built on the groundwork laid in previous research [11-13] by the authors and has been implemented as described in Sections 2.2 and 2.3 with the specific aim of building a strategy system tool able to support the designers, researchers, decision-makers and stakeholders that operate in rural areas both in China and the EU. As regards instead the whole package of materials analyzed, this is described in detail in Section 4.

\subsection{First Work Package, Related Tasks and Results}

The aim of this phase of the research is the definition of goals and strategies to apply in design and planning development in rural areas in order to build an interactive strategy system tool. This task has been built through the semantic analysis of a wide range of literature and documents. With the method of semantic analysis, it is possible to analyze a large typology of sources (texts, video, interviews, photos, sounds) and uncover relationships between a set of documents and the terms they contain by producing a set of concepts related to the documents and terms [14]. The methodology used to achieve that objective is a combination of two complementary and well-known pieces of software: Atlas.ti (Version 6, Scientific Software Development GmbH, Berlin, Germany), a tool used to carry out semantic analysis of several documents, and T-LAB (Version 6.1, T-LAB by Lancia Franco, Roccasecca, Italy), software that enables a classification of the terms used in the documents based on a statistical analysis of co-occurrences. As far as we know, semantic analysis has seldom been used in architecture and landscape design; however, we have moved forward our results in this paper based on the methodology presented in previous research carried out by Dong and Qi on the semantic network method of urban landscape design [15] and by Dong and Zou on the semantic network method of urban design scheming [16]. As regards the semantic analysis procedure, we referred to the examples and methodology on the logic of T-LAB tools by Lancia [17,18]. Notably, T-LAB software is an all-in-one set of linguistic, statistical and graphical tools for text analysis that can be used in research fields, such as content analysis, sentiment analysis, semantic analysis, thematic analysis, text mining, perceptual mapping, discourse analysis, network text analysis, document clustering and text summarization [18]. We apply the T-LAB software as users, and the tools allow us to easily manage tasks, such as the following, among many others:

- Measure, explore and map the co-occurrence relationships between key terms;

- Perform either unsupervised or supervised clustering of textual units and documents, i.e., perform a bottom-up clustering that highlights emerging themes or a top-down classification that uses a set of predefined categories;

- Apply categories for sentiment analysis;

- Create semantic maps that represent dynamic aspects of the discourse (i.e., sequential relationships between words or themes);

- Create, explore and export numerous contingency tables and co-occurrence matrices [18].

The primary source texts have consisted, among many others, of the new urbanization plan for 2014-2020 presented by China's government in March 2014 [19,20]; China's 13th Five-year Plan (2016-2020) [21]; the open archive issued by the FP7 European Project on Sustainable Urbanisation in China [4,22,23]; the EU's rural development policy 2014-2020 [24]; the 2030 Agenda for Sustainable Development issued by the United Nations Sustainable Development Summit in September 2015, which includes a set of 17 Sustainable Development Goals (SDGs) [25].

Following Lancia's methods for semantic analysis, as a starting point, we have explored some similarities and differences between those documents and their subsets, and we have mapped their relationships accordingly [26]. Subsequently, by assuming that the various subsets (i.e., articles, policies) exhibit the main 'themes' (or 'topics') in different proportions, we have considered as analysis units text segments that roughly correspond to an elementary context, and we have partitioned contents into thematic clusters consisting of such analysis units [26]. The T-LAB software enabled recognition of a first thematic bipolarity concerning the rural development: in the top right, the need 
for the implementation of new strategies for building and design; and in the bottom left, for community innovation; whereas the second thematic bipolarity concerns the effects on rural areas' development of the intervention on the environment in the bottom right; and the economy effect in the top left.

The result is a set of goals and strategies, which are the metrics of the semantic diagram, which we have graphically represented in Figure 1 [27-29].

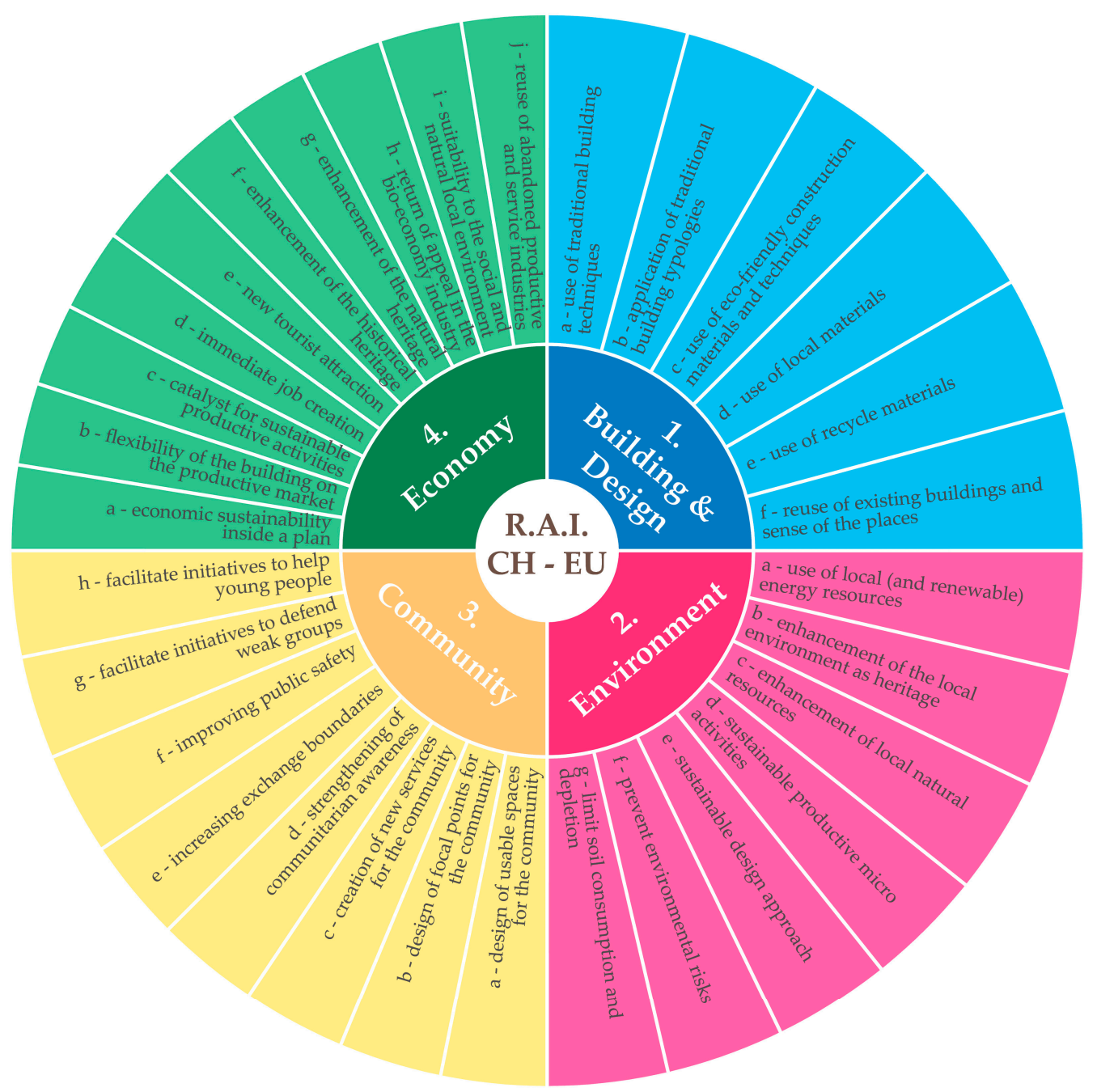

Figure 1. Semantic diagram: goals and strategies for sustainable projects in rural areas.

Four main goals have been subdivided into several concepts, describing the appropriate strategy to apply for rural development. This framework became the main tool for a predictive examination of sustainable projects in rural areas: a strategy system tool, which is an interactive tool able to drive design actions to apply in both the EU and China in specific contexts with specific aims for rural development.

Goals and strategies can be defined as follows:

The goals are:

1 Building and Design: The construction of the building itself is an important action for the transmission of the cultural heritage, the enhancement of the history and of the local business. The design and the construction of the intervention become a key moment in re-enhancing the economy, the environment and the communitarian spirit of the suburbs. 
2 Environment: This means enhancing the quality of the territory, its natural resources, its characteristic elements and the territorial natural systems in which it is inserted (agroforestry, green systems, ecological corridors, etc.). It means paying attention to quality issues while preserving quantitative aspects of the natural heritage. In this category is underlined the ability of the intervention to integrate the environmental aspects with the local activities and with the energetic resources.

3 Community: Who actually makes a place a living place is the community that lives in it; the renewed sense of community is increasingly present in the cultural debate, particularly in the architectural one. New services, places to be shared and focal spaces represent the ability to stimulate a sense of belonging (to a place or to a social group) that strengthens the quality of the intervention and helps to give hope to people, improving their quality of life.

4 Economy: A difficult component to be evaluated and predicted, but likewise important to achieve the objective, is the economic aspect of the intervention, considered both as a set of actions aimed at reviving the productive activities and the employment opportunities and as economic sustainability within a plan at a larger scale. It takes into account the enhancement, in a sustainable way, of the peculiarities of the natural and cultural heritage resources.

The strategies are:

1 Building and design

(a) Use of traditional building techniques: combining technological innovation with building techniques that come from local tradition, employing workers that adopt and transmit the building skills (as cultural heritage).

(b) Application of traditional building typologies: the configuration of the intervention is based on building typologies that come from local tradition, in order to preserve the typological heritage and employ the building typology that best suits the social and environmental context.

(c) Use of eco-friendly construction materials and techniques: the use of building materials and techniques with the aim of reducing the ecological footprint.

(d) Use of local materials: the use of local building material to incentivize local economic activities, bequeath tradition and limit the environmental footprint of the construction.

(e) Use of recycled materials: use of building materials recovered from collapses or demolitions, to reduce the ecological impact and educate regarding the practice of recycling.

(f) Reuse of existing buildings: a design approach based on the search for linkages to pre-existing buildings.

2 Environment

(a) Use of local (and renewable) energy resources: beyond limiting the energy consumption during the construction and life phases of the building, use of locally-produced and renewable energy resources.

(b) Enhancement of the local environment as heritage: protect and support the local natural environment as unique cultural heritage.

(c) Enhancement of local natural resources: promote the cultural, economic and productive quality of the local natural resources, as attractive and endorsing elements of the context.

(d) Sustainable productive micro activities: the productive activities that are hosted or that have been promoted by the intervention are linked with the environmental context.

(e) Sustainable design approach: opt for an ecologically-sustainable approach, both for the construction phase and during the building life (materials, techniques, typology, $0 \mathrm{~km}$, etc.).

(f) Prevent environmental risks: prevent the instability of the land (i.e., hydrogeological and earthquake risk). 
(g) Limit soil consumption and depletion: protect the quality of soil resources and reduce the consumption of soil.

3 Community

(a) Design of usable spaces for the community: create spaces that can be publicly used by the community.

(b) Design of focal points for the community giving a sense of place: create iconic elements and places for the community to foster identity and a sense of place.

(c) Creation of new services for the community: the intervention brings (directly or indirectly) opportunities for new services for the community.

(d) Strengthening of communitarian awareness: intervention that increases the quality of the communitarian awareness and the feeling of belonging.

(e) Increasing exchange boundaries: boost inter-territorial cooperation, relations and exchanges.

(f) Improving public safety: increase the perception of safety among the population.

(g) Facilitate initiatives to defend weak groups: improve the quality of life of weak groups, such as the elderly and children, by creating spaces and developing services addressed to them.

(h) Facilitate initiatives to help young people: create environments where working, business and residential opportunities addressed at young people can easily be developed.

4 Economy

(a) Economic sustainability within a business plan: the economic and productive impact is evaluated as sustainable within a wider economic plan.

(b) Flexibility of the building in the productive market: the intervention sets up productive flexible spaces that can accommodate activities capable of reorganizing themselves, once the market changes.

(c) Catalyst for sustainable productive activities: the intervention promotes the creation or strengthening of sustainable job opportunities for the community.

(d) Immediate job creation: direct creation of new jobs employed in the activities hosted or promoted by the new intervention.

(e) New tourist attraction: development of the local tourist appeal, due directly to the intervention.

(f) Enhancement of the historical heritage: the intervention enhances the local historical heritage with consequent tourist development of the context.

(g) Enhancement of the natural heritage: improvement of the quality of the natural patrimony with the consequent increase of tourist appeal.

(h) Return of appeal in the bio-economy industry: support bio-agriculture activities through short chains, landscape cultivation preservation, diversification and innovation.

(i) Suitability to the social and natural local environment: the productive activities are suited to the social context and the natural resources.

(j) Reuse of abandoned productive and service industries: recovery of the existing building heritage, renewing it through functional and spatial interventions and linking it to the local economic system.

The diagram depicts relations among goals and strategies. For instance, here it is possible to create associations from goals showing relations with strategies about a specific project's aims. The semantic diagram presents graphically goals and strategies for sustainable projects in rural areas. It may be aimed at policymakers, stakeholders, researchers, designers and/or some other groups of citizens' communities whose development actions are undertaken in a specific rural context.

This set of goals and strategies represents a suggestion of approaches to be applied in the territory for designing the sustainable development of rural areas. However, it should be clearly marked that 
this tool cannot give any indication on the priority of the adoption of the different strategies. In fact, it is not conceived of as an assessment tool. The choice of which strategies to apply, or what strategies have priority over the others belongs to the cultural understanding of the users, who have to know the specific condition of the context. Therefore, the tool is created to provide a set of strategies to be applied to different realities combined by similar problems, but it cannot indicate which strategies are more important than the others, which is the duty of the tool users. Thus, the ostensible conflicts that arise among the subjects identified by the goals (economy vs. environment; community vs. economy; building vs. environment, etc.) disappear when the tool is applied, by the users, to each local area. Therefore, for example, in a given context, the attention to the environmental issue will be greater than to the economic one, and vice versa, in another reality, the attention to the economic aspects will need more consideration with respect to the environmental topics.

Users are free to transition from one into the other; the building and design produces vision changes in behavior that are perceived by the community. The community produces a new perception of the environment inspiring new demands and new functions. The environment produces benefits and awareness that can inform the economy, and so on. It is a cumulative process in which users can create repetition, continuity or changes. In a specific context, for instance, the tool generates some contents, other contents are exhausted, some are released and new contents can be created.

This process should be improved in the future, developing the tool also from the point of view of evaluation, making it capable of hinting also at the action priorities, avoiding the ostensible conflicts between the choices to be made.

\subsection{Second Work Package, Related Tasks and Results}

The second work package is complementary to the first one and includes two tasks. The objective of this phase of the research has been the application of the strategy system tool in two selected areas (one in the EU (Italy) and one in China (Fujian)), specifying the main aims to achieve in those specific contexts. In addition, we verify and adapt the strategy system tool through two meta-projects on two selected rural areas designed based on the design tactics deduced from the interaction between the aims and concepts of the strategy system tool. The meta-projects [30] allowed us, on the one hand, to envision the architectural development of the selected rural areas and, on the other hand, to confirm the validity of the whole research framework.

The method can be summarized in six fundamental steps as follows:

- $\quad$ List the four goals and the related strategies of the strategy system tool;

- Analysis of the territory (site survey included) to identify the characteristics and sensitivity of the territory in both the natural and social aspects, anthropic pressures present therein, the needs of local communities, comparing these to the regional context to find any homogeneity or discontinuity;

- Definition of the main aims (short-term and long-term objectives);

- Definition of specific design tactics in an attempt to give practical answers to the main aims;

- Creation of meta-projects that represent possible solutions to the needs of developments and innovations of the specific context;

- Verification and qualitative evaluation of the meta-projects. Comparison of the results arising from the verification of meta-projects querying the strategy system tool, determining the best potential solution as a cue for the beginning of the real design phase.

To this end, two diagrams, which represent the application of the strategy system tool, have been designed.

The diagrams in Figure 2 and Figure 7 are divided into three columns:

- first column (objective data): aims, which are the objectives to achieve for the development of the specific rural areas under investigation. 
- $\quad$ second column (objective data): strategy tool, which is the list of the goals and strategies as defined in the first work package and depicted in the semantic diagram in Figure 1.

- third column (subjective data): design tactics, which are the concrete design actions to apply in the selected areas.

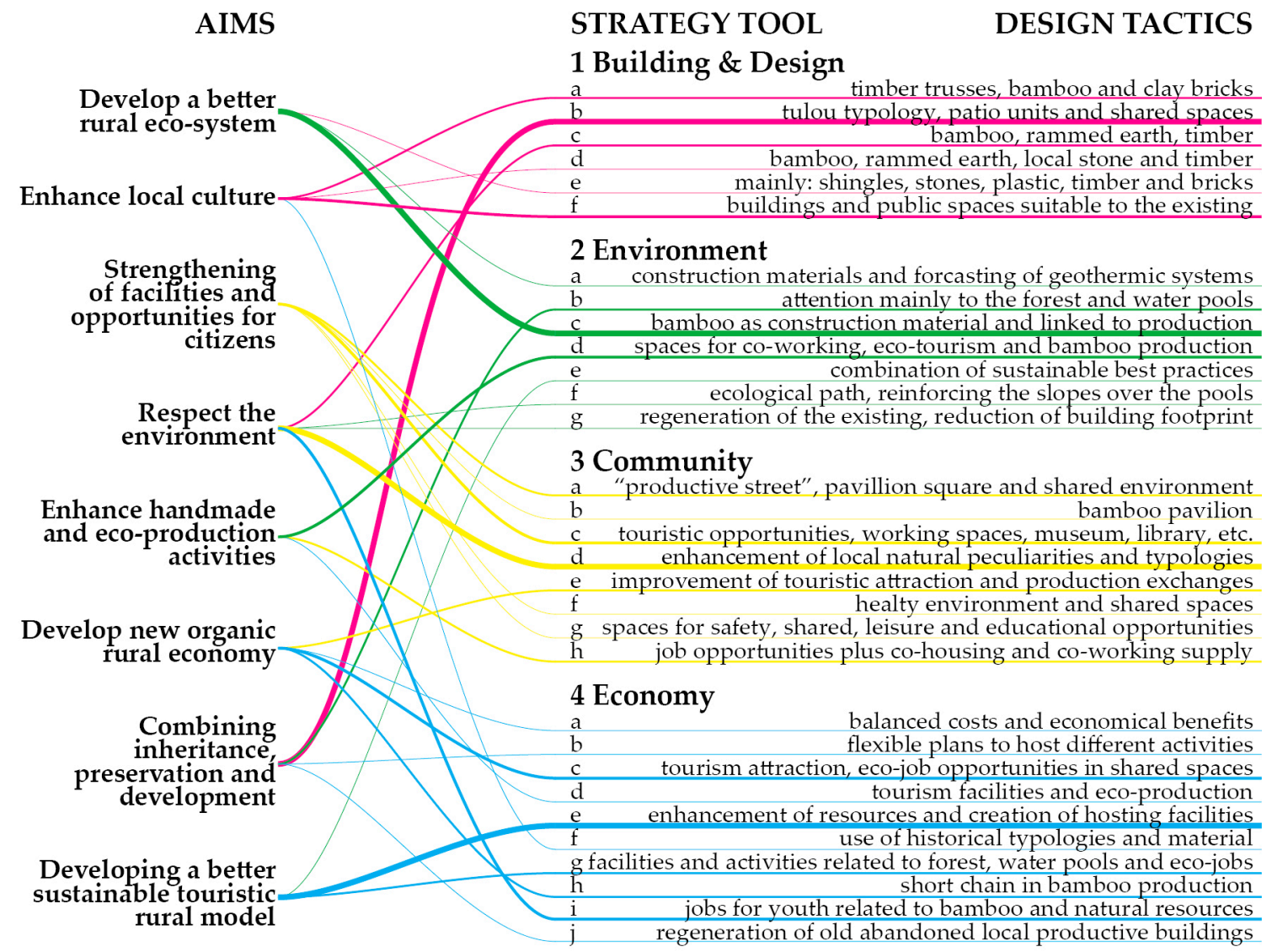

Figure 2. Diagram application of the strategy system tool. Meta-project 1.

The first column and the second column are objective data. They are observable data obtained through observation, analysis and physical examination, documents, policies and literature study. Notably, the second column represents the concepts of the strategy system tool created by the semantic analysis previously mentioned. The materials used are described in detail at Section 4 .

The third column represents subjective data, which represent the design tactics deduced by the designers through their understanding of the context and design sensibility.

The connections and relations between the three columns represent the guidelines to follow in order to achieve the best design solution in the specific context under investigation.

\subsection{Meta-Projects}

Two meta-projects have been designed applying the guidelines resulting from the strategy tool diagrams. The logical process of design operations (as amply described in the literature) is an iterative process that provides for the definition of general and specific objectives as determined from time to time by stakeholders, public administrations, decision-makers, public or private associations, entrepreneurs and also designers. This article does not intend to present a detailed and analytical description of the buildings themselves, but we believe it is more important to outline the design outcomes arising from verification of the meta-projects through the application of the strategy system tool. Discussions about the criticism and potentialities of the application are presented thereafter. 


\section{- $\quad$ Meta-project 1}

This project is located in the Chinese rural context of Fujian Province near the Changtai Mayangxi scenic spot, where the demand for touristic supply is increasing with the growing of GDP and wealth [31].

Defining design tactics able to combine the preservation of natural and historical heritage, the development of new touristic models and the relaunch of agricultural and craft activities is the challenge proposed for this project. In contrasting the traditional way of life and urbanization of the countryside, great importance is given to the 'rural makers': a combination of people skills and new facilities that foster innovation and tradition can provide better ways of living.

As highlighted by the diagram in Figure 2, the design tactics have involved all of the strategies proposed by the tool.

In particular, for the goal of building and design, the traditional typologies of the tulou (common residential building typical of Fujian Province) $[32,33]$ and the residential units with small courtyards or patios [34] have been applied to the new constructions, in order to enhance the cultural heritage and communitarian awareness of local people. With the same aim, natural resources such as the lakes and forest have also been included in the project as main common elements to enhance. According to this vision, the widespread natural resource of bamboo, considered as a symbol of oriental culture, and thanks to its features of being a renewable material and its superstructural strength, becomes the main construction material and the natural element for the activity of handmade crafts. The main characteristics of the meta-project 1 are visualized in Figures 3-6.

\section{- $\quad$ Meta-project 2}

The context of this European project is the Italian productive countryside between the cities of Milan and Pavia.

The main aim of the project is to give a new value to the agricultural landscape that nowadays has completely lost any relation with the natural and historical environment. An abundance of water and a dense network of irrigation channels characterize the countryside of the region around Milan [35]; these channels are not only means for the agricultural activities, but, even if nowadays forgotten, they are also an element of the landscape of this territory [36]. The current industrial agriculture compels the use of chemical products to increase efficiency, but it destroys the richness of the ecosystem and it distances people from enjoying this common good, rich with historical heritage and natural biodiversity.

As can be seen, among the design tactics in Figure 7 chosen to work within this environment, the idea of reusing existing buildings, historical paths and connections in the landscape has been very important, in particular relating this activity to the restoration of landscape as an element of identity for the community [37]. Therefore, the sustainability for rural settlement comes from the participation of the community, but also from the attention to the environment and economy: tools for different clean energy supply and the settlement of facilities related to agriculture and eco-jobs have been the main tactics for the project. The main characteristics of the meta-project 2 are visualized in Figures 8-10.

At the end of the second work package, we can briefly summarize critical considerations regarding their values. Considering the meta-projects as case studies, one of the most cited books on the case study research, by Robert Yin, provides the following definition: 'A case study is an empirical inquiry that investigates a contemporary phenomenon within its real-life context, especially when the boundaries between phenomenon and context are not clearly evident' [38]. As Groat and Wang argued, that means the essence of the case study strategy is its focus on studying a setting or phenomenon not embedded in its real-life context. As Yin describes it, the case study strategy implies much more than simply studying a phenomenon in the 'field'. Rather, the case study involves studying a case in relation to the complex dynamics with which it intersects and from which the case itself is inseparable [39]. 


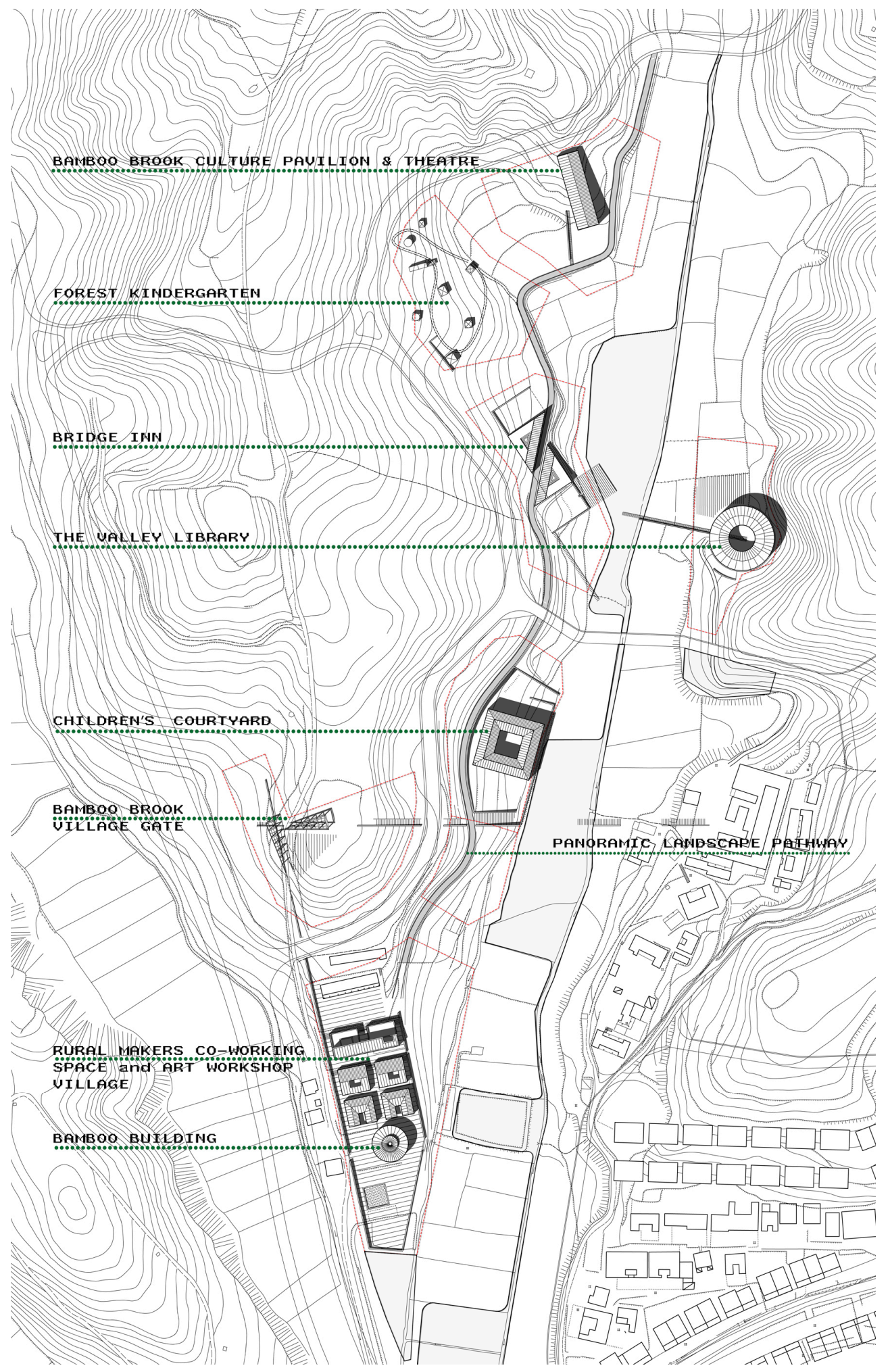

Figure 3. Master plan of the village. Notably, the new functions create a landscape visual interaction between nature and artifacts. 


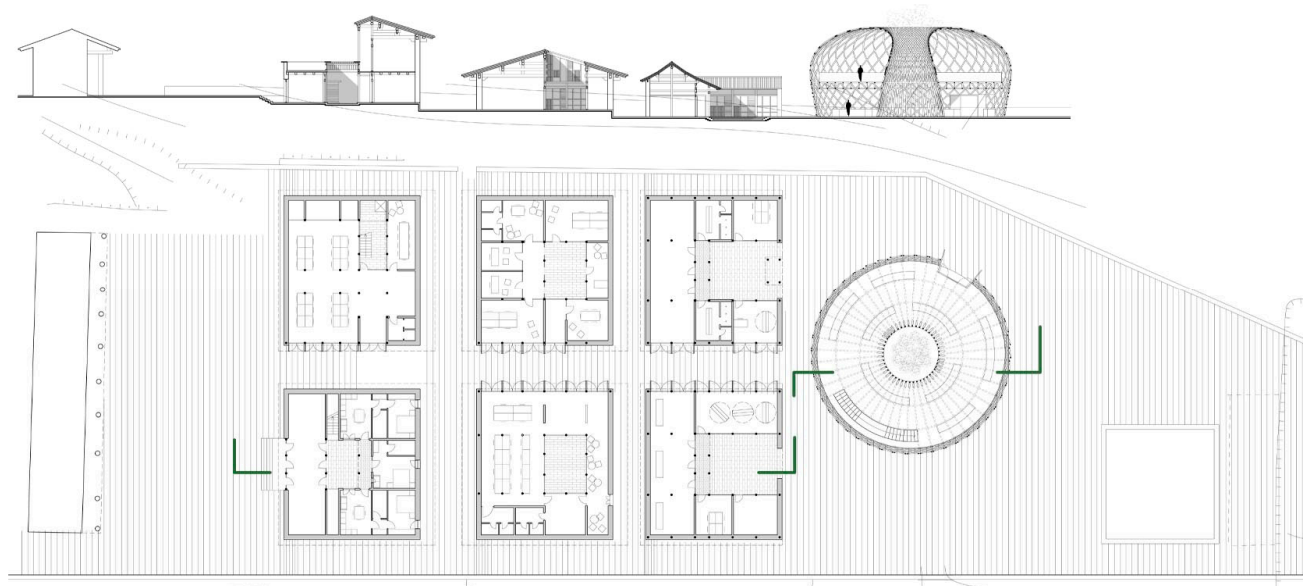

Figure 4. Plan and section of the rural makers' co-working space, the art workshop village and the bamboo building.

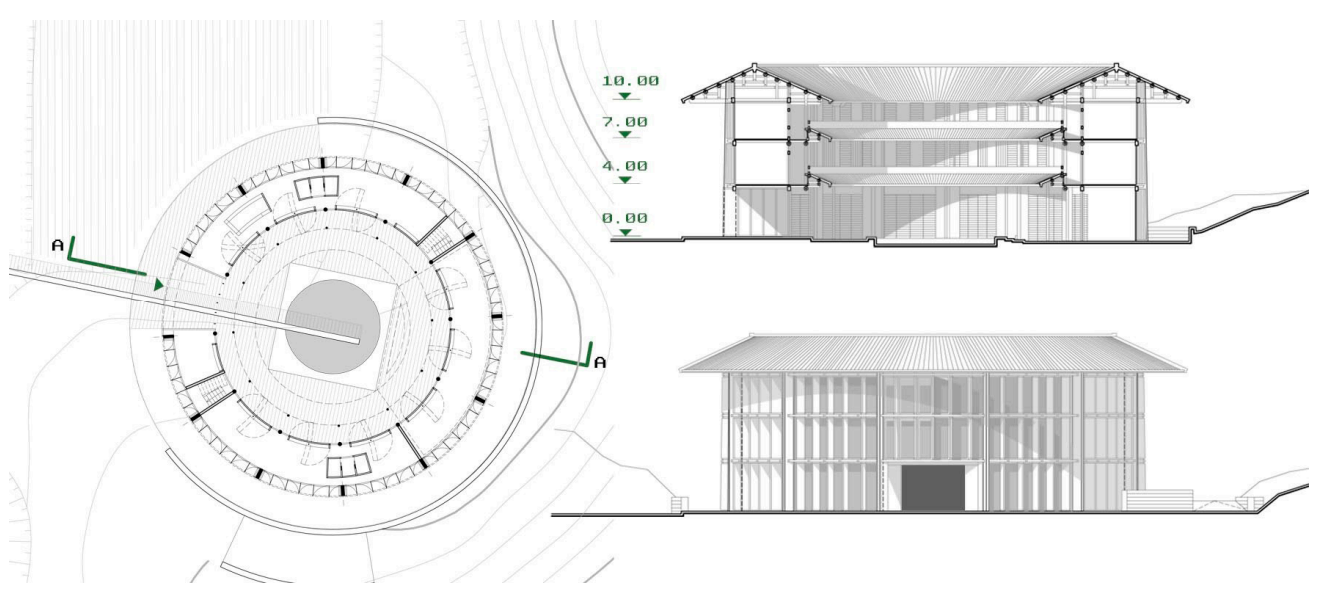

Figure 5. Plan, section and façade of the valley library designed starting from the tulou typology.

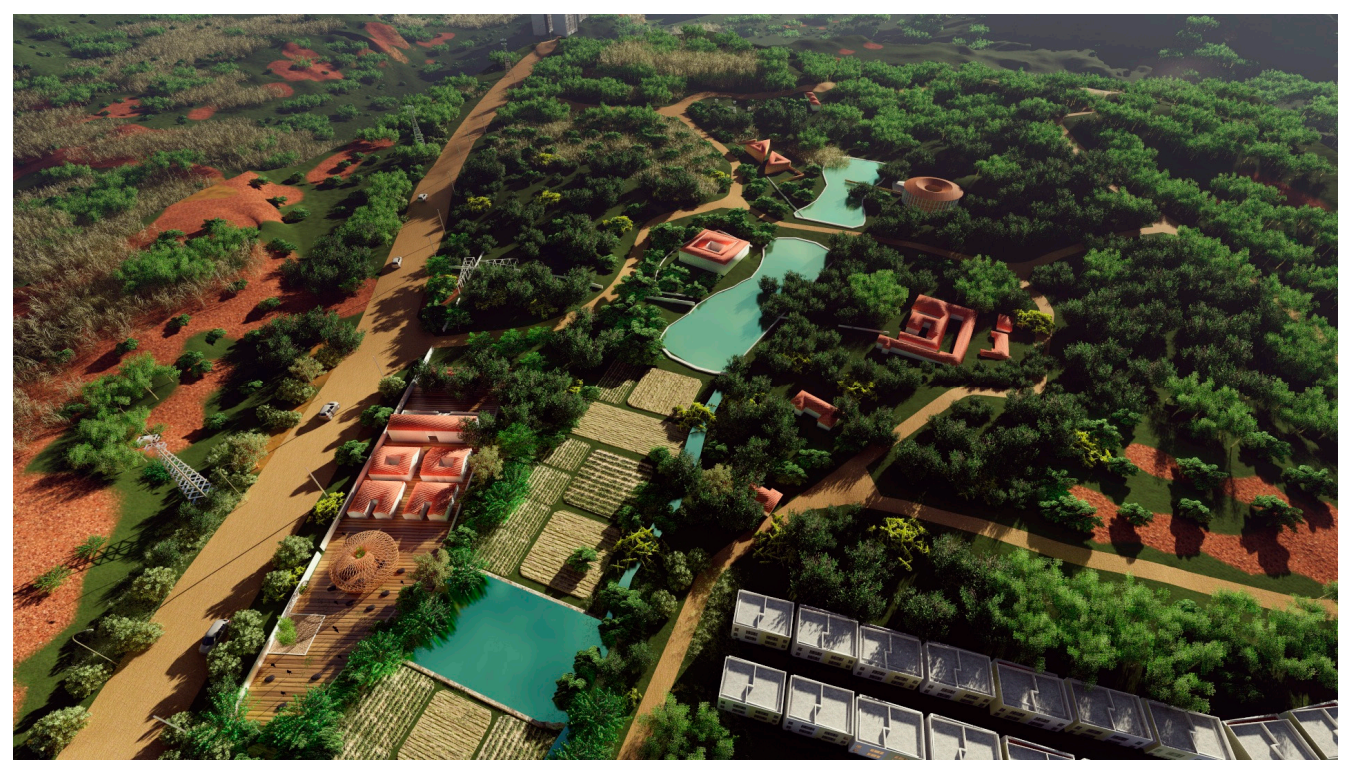

Figure 6. Aerial view of the village, by Francesco Grugni for China Lab. 


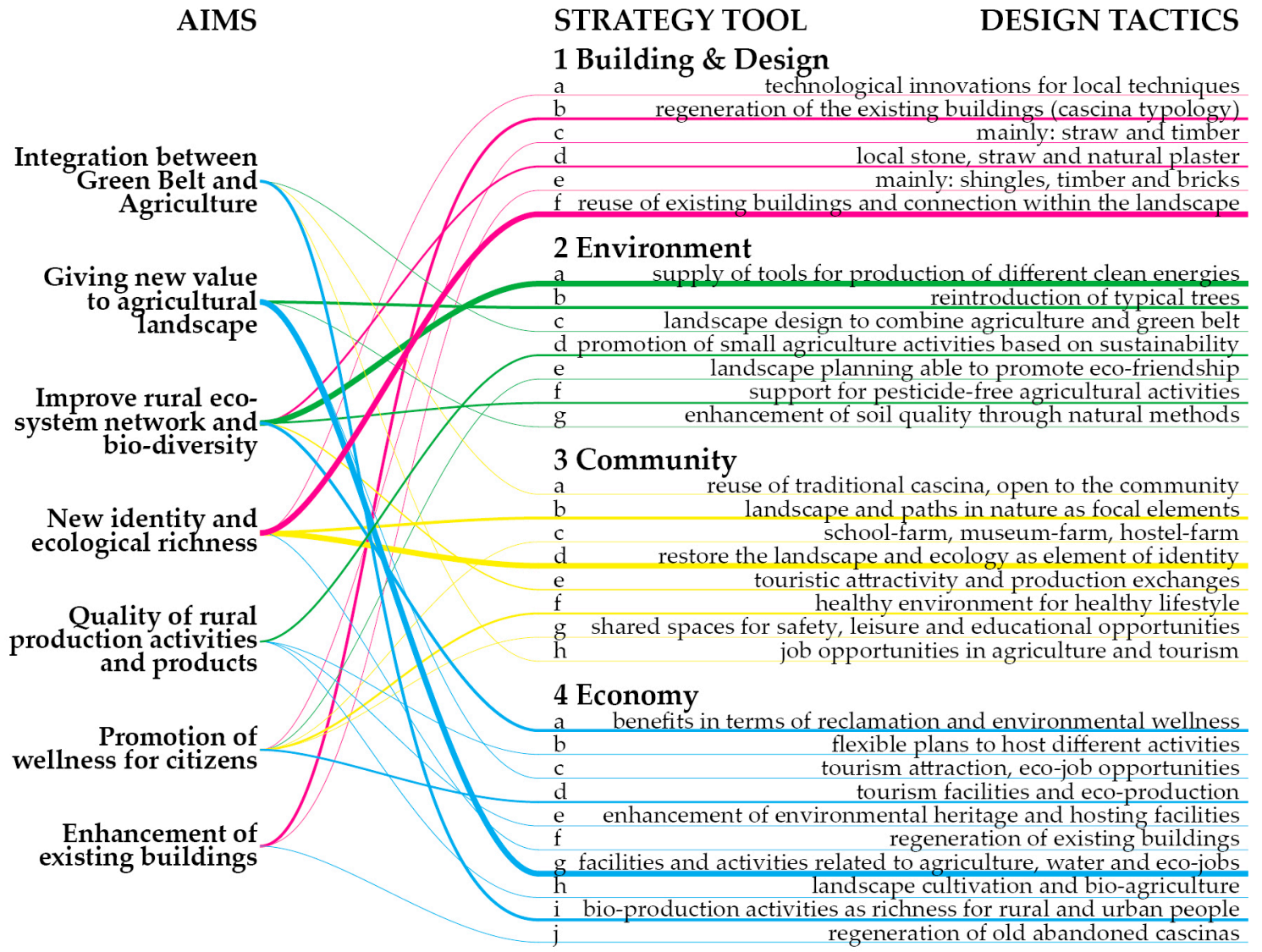

Figure 7. Diagram application of the strategy system tool. Meta-project 2.

Despite the fact that the workability of the 'strategy system tool' needs to be deepened in its effectiveness, we can affirm that it is possible to see, as the tool contains goals and strategies capable of giving answers to the various aspects (economic, social, environmental and construction), and propose solutions to the needs analyzed in the specific contexts of these two projects. Thus, the tool provides guidelines to drive possible design solutions for the problems of both realities investigated.

Furthermore, the strategy system tool is able to inform the design at different scales: from the territorial scale to the landscape design and architectural design assisting the users (such as designers, investors, policymakers together with other stakeholders) in the most general technical and non-technical strategies, such as, for instance, construction materials linked with the context, functions able to improve the economy of the community, building typology linked to the tradition of the place, innovation in terms of green technology, landscape design linked to economic sustainability, etc. Of course, it is necessary to clarify that from the point of view of the building's formal results, different designers could give different solutions, but the validity of the strategy system tool is in the fact that any subjective choice is driven within the framework of the strategy system tool itself, which has been drawn to achieve results in terms of social, economic and environmental sustainability. In doing so, the meta-project case studies can, like experiments, be explanatory. Whether a particular case study is explanatory, descriptive, exploratory or some combination of these is a function of the researcher's purpose rather than any limitation inherent in the case study strategy [39]. 


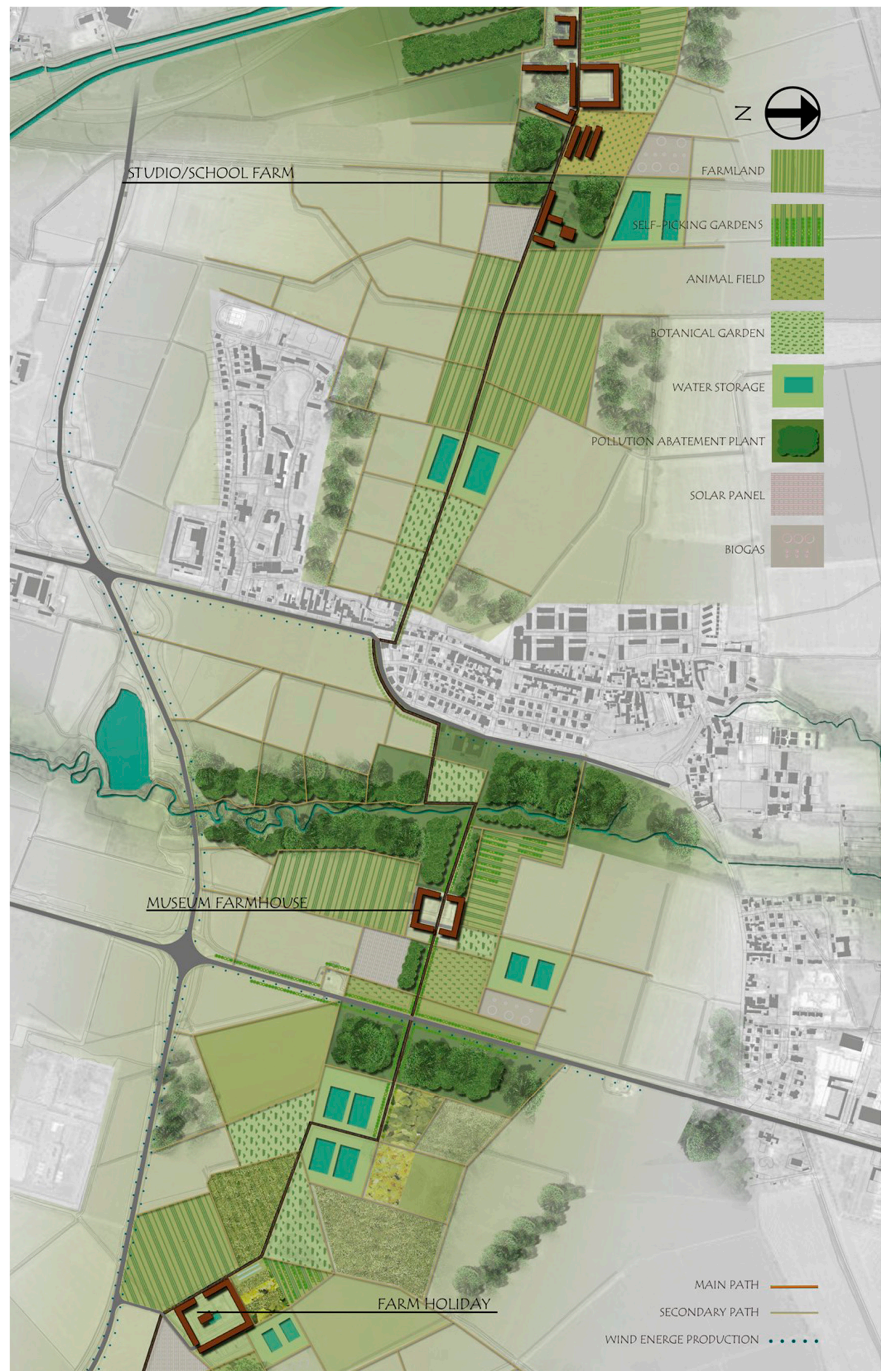

Figure 8. Master plan of the farmhouse (cascina). Notably, the new functions create new connections in the rural landscape and new visual interaction between agriculture, public spaces and historical buildings. 


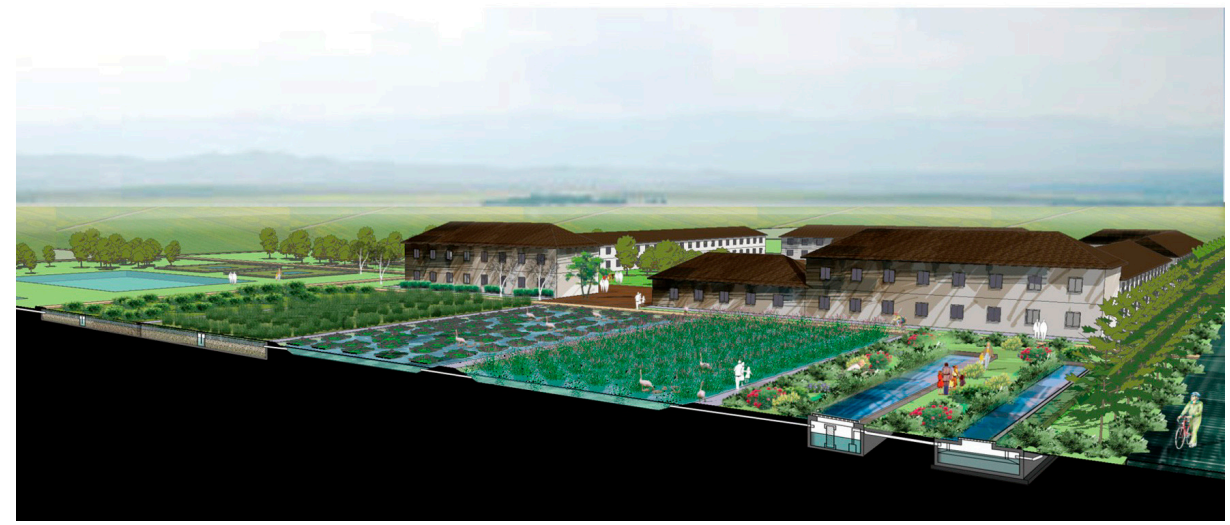

Figure 9. Prospective section of the existing farmhouse (cascina) regenerated and the new landscape designed as public space and energy production through water system.

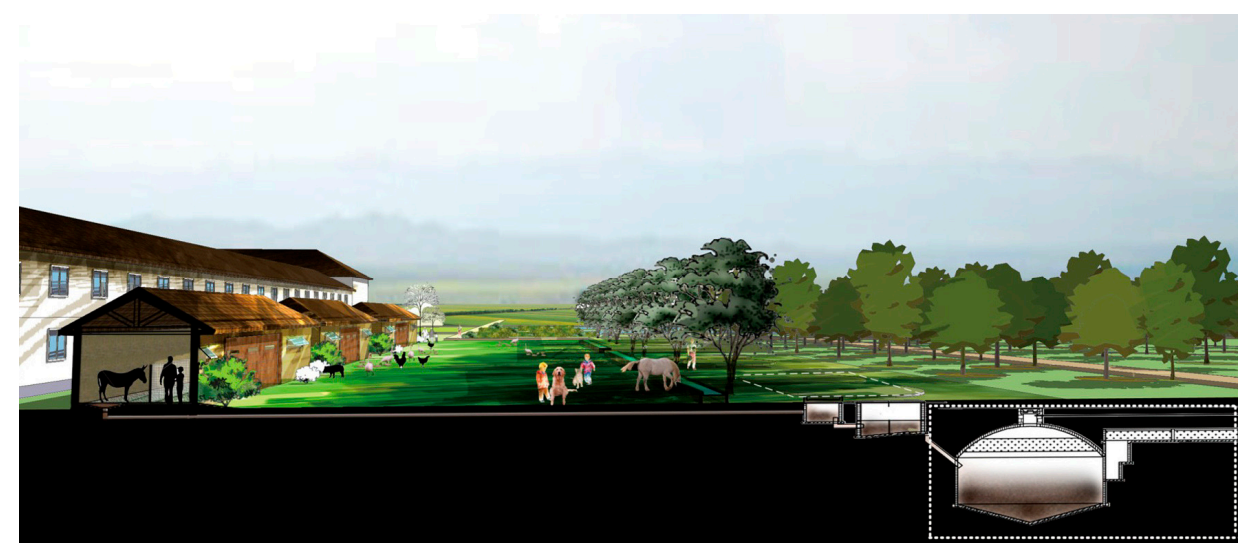

Figure 10. Prospective section of the existing farmhouse (cascina) regenerated and the new landscape designed as public space and energy production through biomass.

\section{Discussion}

The set of goals and strategies, the result of this research, is a strategy system tool capable of supporting the understanding of rural areas both in China and the EU. The goals and strategies are not to be read only by points, but, as much as possible, they should be related to each other, both within the same group and between different groups. Moreover, the possibility of comparing projects in different locations is achieved by the fact that specific considerations on the context are not directly present in the strategies supplied in the tool. In particular, the structure of this tool can be applied to several fields:

- Research: It can be used as a reading tool by researchers, who can approach the reading and the comparison of rural architecture projects both in China and the EU. The strategy system tool must be considered a reading tool that can be related to every place; in effect, it does not refer to a specific context. Its possible application in a specific context should be introduced in the second step of investigation, namely when the research starts to analyze the set of goals and strategies in relation to the local features in terms of materials, typology, construction techniques, environment, community structures, local businesses, etc. Therefore, we can conclude that the local context is strongly taken into consideration in the investigation step of the project's reading, thereby allowing a transversal comparison among different contexts [40]. Obviously, researchers are required to express their sensitivity in the observations/investigation of the ongoing phenomena in a specific place. 
- Design: the strategy system tool can also be used as guidelines for the designers in both Chinese and EU rural areas. Through the application of the semantic diagram, designers can create their own project framework to define design tactics to apply at the project site. As already stated, the specific context features are not included in the system itself, but must be considered case by case by the designers. This means that suitable application of the proposed strategy system tool depends on the sensibility of the designer. Designers are required to express their ability to imagine and depict non-existent environments, such as future conditions originating in their minds, as well as lost environments from the past. Imagining and representing non-existent environments refers to both the material features of places and intangible values; the latter aspects are difficult to grasp. Even if the designer consciously addresses in his or her design the sense of place, the anticipation of it is difficult to communicate and test. Intangible values are expressed and revealed in very different ways by designers during conceptual design. In any case, it is very hard to assess how designers control the future ambiance in a scientific and sharable way [41].

- Decision-making: The strategy system tool can also be used by those institutional and non-institutional bodies that have to make decisions on the future development of rural areas. In fact, the proposed tool aims to support local governments, citizens' associations, communities and entrepreneurs in making the best decisions for local sustainable development. With the aid of the proposed system, stakeholders can understand easily and more quickly which goals and strategies better fit their needs in the specific context in which they are operating [42]. The main applications in rural areas for all of these institutional and non-institutional bodies could be, among many others, the creation of policies, the definition of best practices, the definition of planning and architectural rules, the definition of local guidelines for community creation and social engagement, etc.

Furthermore, it is interesting to underline that this tool has no purpose as an evaluation tool for the projects. In terms of 'evaluation', it would require coefficients to weight all of the parameters. In particular, we are strongly convinced that these weight coefficients would depend on the features of the local context analyzed. Therefore, the system retains the possibility of being applied in various geographical areas.

The tool must not be understood as vague and generalized, but rather as applicable to a wide series of rural settlements with distinctive and unique features. In fact, as repeatedly stressed in the paper, the tool aims to give directions, of a strategic nature, that can be used in different contexts, providing indications applicable, thanks to the cultural understanding of the users, to a whole range of cases, making the strategies, initially free from the context, design tactics suitable to a specific local area. As described at the beginning of this paper, European and Chinese rural areas are experiencing very similar problems, albeit arising from different socio-cultural economic reasons. Therefore, it was possible to develop a tool that proposes common intervention strategies.

In particular, it seems useful to underline that the basic knowledge of this paper also derives from the analysis and comparison of a huge number of realized projects in both the EU and Chinese rural areas. The project database and results of those previous studies by the authors, which, for clear reasons of originality, do not appear again in this paper, are available at the website www. raintensification.com and have already been presented, exhibited and published in several conferences and publications $[13,43,44]$.

An advantage of this tool is that it represents a meeting point among different professional sectors (research/design/decision-making). Keeping the purpose of preserving this tool's feature, we imagine the evolution of our strategy system into an E-tool capable of remaining exploitable for a wide range of aims. In this way, imagining the future development of the semantic diagram into an interactive tool implementable directly by the users (researchers, designers and decision-makers), it is possible to forecast that they could easily take mutual advantages from a wide range of outputs achieved from the work shared by the same users. Hence, the result of this research is an open system that could be implemented by users, becoming a software-based system able to produce design strategy 
outputs starting from inputs inserted by researchers, designers and decision-makers according to their needs and to the features of the specific context. Making our system a computer-based system means providing an interface to the tool, which facilitates the decisional and organizational processes. In this way, we can consider the future development of our design-strategy system as a decision support system (DSS), if not even a decision-making software (DMS), which are intended to support the analysis during the decision-making process, focusing the attention on the fundamental values and features of the analyzed context.

Keeping this idea of an interdisciplinary DSS/DMS, future implementations of the presented results could be:

- A mobile application to be developed in cooperation with specialized developers and researchers, capable of developing an easy interface to be used by smart devices. In this way, everybody may have access to the tool and use it directly.

- An open-source collection of rural architectural intensification case studies in the European and Chinese contexts to be consulted, examined and also implemented by the users. This collection will offer several case studies to be used as references, but also material for wider qualitative investigations and improvement of the tool itself.

\section{Materials}

\subsection{Materials and Documents Analyzed by Semantic Analysis Software}

As previously mentioned at Section 2.1, a huge number of sources has been analyzed and processed with the semantic analysis software. However, the widest range of materials and resources of investigation come from the open-access archive of the research issued by the FP7 European Project on Sustainable Urbanisation in China, well known as UrbaChina [4,22,23].

The UrbaChina project has been funded under the European Commission's Seventh Framework Programme. UrbaChina is structured as a collaborative project managed by a consortium of 11 leading Chinese and European research institutions. Coordinated by the CNRS (France's National Centre for Scientific Research), its project coordinator is Professor François Gipouloux. The UrbaChina archive [45] provides a large range of results and outstanding analysis on China's urbanization trends for the next 40 years and provides possible future scenarios with reference to concepts of sustainability.

This paper places strong emphasis on the cooperation between the EU and China as delineated in the Introduction, and our research comes up beside the UrbaChina research project. Aware of the fact that Europe and China have followed different urbanization paths, there is nonetheless room for mutual learning. By the way, one of the main objectives of the UrbaChina project, and this project also, is to strengthen the collaboration between Chinese and EU researchers and policymakers driven by the common goal of building sustainable cities together with the development of rural areas.

In order to clarify the materials and documents processed with semantic analysis software, we think a brief description of the UrbaChina results is merited here.

The UrbaChina website provides an open-access working document collection [45] divided into several sections as follows:

A collection of working papers is hosted on HAL (Hyper Article en Ligne) [4] and gathers together several papers focusing on the main themes of the project: institutional foundations of urbanization, territorial expansion of Chinese cities, urban communities and urban sustainability.

UrbaChina's final presentations were held during the conference in Paris, 15-16 January 2015 [46].

The Urban Futures-Squaring Circles: Europe, China and the World in 2050, proceedings were held in Lisbon, 10-11 October 2014 [20].

Policy briefs section in which UrbaChina partners present their findings and results related to topics on sustainable urbanization trends in China. They also provide several recommendations to accelerate transition toward sustainability [47]. 
UrbaChina blog is a collection of the latest news on four specific themes regarding urbanization in China: the institutional foundations and policies for urbanization, the territorial expansion of Chinese cities, the infrastructures and services for sustainable urbanization, the building of urban communities [48].

UrbaChina photo collection is a compendium of images available in an open-access archive [49]. This collection currently contains photos provided by members of the UrbaChina project, including Miguel Elosua, Sébastien Goulard, Ai Chi-Han, François Gipouloux, guests, Fu Jie. The objectives of the photo collection could be described as follows:

- To provide images of the four cities under study in the UrbaChina project: Shanghai, Huangshan city, Chongqing, Kunming

- To provide iconographic documents on urbanization in China

- To store the photos used by the UrbaChina partners and available for further investigations.

The whole corpus of data delivered is available to be studied in depth and analyzed in order to create new understanding, insights, ideas and new further research and results.

\subsection{Materials, Documents and Cartography for Meta-Project Design}

In order to link the meta-project design with the real problem of the context, a preliminary site survey to investigate the environment was carried out. Along with this obvious first step, many other documents have been investigated and analysis on the context carried out.

The basic materials examined for each specific context (one in the EU (Italy) and one in China (Fujian)) are listed as follows:

- Materials and cartography of the Changtai Mayangxi scenic spot, Fujian, China, provided by the website of the Architects in Mission (AIM), Bamboo architecture design competition, for the village of rural makers [50];

- Digital and non-digital map archive of the Institute of Architecture and Urban Studies of the College of Architecture and Urban Planning of Tongji University. The archive is not open access. Researchers interested in using the files of the above-mentioned archive need to make a formal request to Tongji University. The authors obtained temporary access to the archive thanks to the long-term collaboration between the members of China Lab of the University of Pavia and the Institute of Architecture and Urban Studies;

- Photo collection provided by the authors;

- Materials and cartography of Pavia Municipality city master plan [51] described in detail as follows:

'Documento di Piano' (DDP): This is the fundamental document of the city master plan. It is a rules' apparatus that defines the strategies, objectives and actions through which an overall framework of socio-economic and infrastructural development of the city is reached, considering the environmental, landscape and cultural resources as essential elements to be enhanced. In particular, the tables: Table DDP 05, Landscape Charter, scale 1:10,000; Table DDP 06, Landscaping Sensitivity Charter, 1:10,000; Table DDP 07, Charter of Soil Use, 1:10,000; DDP Table 08, Municipal Ecological Network, Guideline Schema, 1:10,000; Table DDP 09, Agricultural areas in the state of facts, under the Decreto Giunta Regionale (D.G.R.) Lombardia 22-12-2008 No. 8-8757-1:10,000;

$\bigcirc$ 'Piano delle Regole' (PDR): This is the document that provides the building regulations for the whole municipality territory. It is a list of instructions for the management of the consolidated urban fabric, as the whole of parts of the territory on which the building, or conversion of the building, has already taken place, including free enclosed and completed areas. It identifies and indicates the discipline for the areas selected for agricultural 
production, the landscape and environmental value areas and those portions not subject to urban transformation. In particular, PDR Table 07, Cascine, 1:10,000 has been studied. Notably, in the municipality of Pavia administrative boundaries, there are 117 farms, of which: 12 farms need new functions; 50 farms are abandoned, with non-agricultural functions; and 55 farms are still in active production with main agricultural functions;

- The Environmental Report for Strategic Environmental Assessment, which identifies, describes and evaluates the significant impacts on the environmental components coming from the fulfilment of the city master plan; it contributes to the definition of the objectives and strategies of the whole planning, showing the criteria for environmental compatibility, the reference indicators and the directions for environment monitoring;

Incidence study, which identifies and assesses the possible impacts of the city master plan on the natural species and habitats, particularly on the 'Natura 2000' sites.

- Digital and non-digital archive of maps, at different scales, available at the Department of Civil Engineering and Architecture of the University of Pavia. Notably, the team of designers, authors included, of the Department were in charge of the scientific consultancy for the preliminary design of the Pavia city master plan. The archive is not online and is available at the library of the above-mentioned Department.

\section{Summary and Conclusions}

This paper makes an important contribution to moving beyond the knowledge of the articulated architectural and social evolution of rural areas, looking at the local and global challenges, at the need for continuous adaptation and at the experiences of resilience that the countryside faces today, for which it will be a valid paradigm for Europe, China and, maybe, many other territories in the world [33].

Key results include:

1 New insight into development opportunities for EU and Chinese rural areas and their current planning and action agenda for future sustainable growth.

2 Construction of a rural semantic diagram, which represents a metric for trans-scalar support for decision-making and design; a set of indicators that represents crucial properties and priorities for architectural heritage and rural settlements.

3 Construction and visualization of predictive design patterns for rural areas in both the EU and China and an alternative vision for the analysis, design and simulation of these contexts.

4 Comparative studies between the EU and Chinese territory (which could be extended to other world areas) in their own phase of development.

The research is developed around the observation of the evolution of the rural territory of Fujian, China, and the Lombardy region in Italy as a paradigmatic example of the ongoing ruralization phenomenon; however, the approach that has been developed is also adaptable and will be applicable in a wider context in the EU, Asia and in other parts of the world.

Acknowledgments: The research project has been performed within the China Lab. for Architecture and Urban Studies at the Department of Civil Engineering and Architecture of the University of Pavia (Italy), thanks to its network, its funds and members. China Laboratory is both a Laboratory and International Research Network, which operates in both Italy and China, and conducts research inspired by China's rapidly progressing urbanization, including also the architecture production and rural-urban space (www.chinaurbanlab.org). The authors acknowledge Architect Paolo Bacci of the University of Pavia (Italy) and Arch. Massimo Corsico (Italy) for their participation and contribution in designing the first meta-project; and Engineer Francesca Castelli and Engineer Riccardo Gallini of the University of Pavia (Italy) and Architect Liu Yeyao of Tongji University in Shanghai (China) for the design of the second meta-project.

Author Contributions: Tiziano Cattaneo is the scientific coordinator of the overall research project. Each author has contributed equally to the development and writing of this paper. The drawings and the schemas in this manuscript have been devised and provided by the authors and the collaborators of China Lab. 
Conflicts of Interest: The authors declare no conflict of interest.

\section{References}

1. Beuret, J.-E.; Kovacshazy, M.-C. Rural amenities policies: Future stakes. In Amenities and Rural Development. Theory, Methods and Public Policy; Green, G.P., Deller, S.C., Marcouiller, D.W., Eds.; Edward Elgar: Northampton, MA, USA, 2005; pp. 33-47.

2. Potocnik, J. Guidelines on Best Practice to Limit Mitigate or Compensate Soil Sailing. European Commission, 2012. Available online: http://ec.europa.eu/environment/emas/news/archive_en.htm (accessed on 15 January 2016).

3. Prokop, G. Corine Land Cover Technical Guide; Technical Report No 17/2007; European Environment Agency (EEA): Copenhagen, Denmark, 2007.

4. HAL-UrbaChina Open Archive. Available online: https://hal.archives-ouvertes.fr/FP7/ (accessed on 14 February 2016).

5. Leader Plus Initiative. Available online: http://ec.europa.eu/agriculture/rur/leaderplus/index_en.htm (accessed on 12 May 2016).

6. European Union, Regional Policy Urban-rural linkages, RURBAN. 2010. Available online: http://ec. europa.eu/regional_policy/en/policy/what/territorial-cohesion/urban-rural-linkages/ (accessed on 15 January 2016).

7. Sha, Y.; Wu, J.; Ji, Y.; Chan, S.L.T.; Lim, W.Q. Shanghai Urbanism at the Medium Scale; Springer: Berlin/Heidelberg, Germany, 2014; pp. 1-5.

8. Sha, Y. Chinese city in transition: Problems in the rapid city-making and possible amendments. In Urban and Rural Planning-Chinese City Transformation; Urban and Rural Planning Editorial Committee, Ed.; China Architecture \& Building Press: Beijing, China, 2012; pp. 4-14.

9. European Union. Joint Declaration on the EU-China Partnership on Urbanization. Available online: http: / /eeas.europa.eu/delegations/china/eu_china/sustainable_urbanisation/sustainable_urbanisation.htm (accessed on 04 April 2016).

10. Groat, L.; Wang, D. Architectural Research Methods, 2nd ed.; John Wiley \& Sons: Hoboken, NJ, USA, 2013; pp. 443-444.

11. Cattaneo, T.; Sha, Y.; Ji, Y. Architectural design strategies for the rural development in Europe. In Urban Architecture (UA); Heilongjiang Science and Technology Press: Harbin, China, 2015; pp. 109-111.

12. Cattaneo, T.; de Lotto, R. Rural-Urban-Architecture. Design Strategies for Small Towns Development; Alinea Editrice: Florence, Italy, 2014; pp. 29-69.

13. Cattaneo, T.; Sha, Y.; Giorgi, E.; Manzoni, G.D. Identity+Innovation: How to give hope and opportunities to forgot suburbs. A comparative study between EU and China. In Heritage and Technology. Mind Knowledge Experience, Proceedings of the Le vie dei Mercanti, XIII International Forum, Aversa-Capri, Italy, 11-13 June 2015; Gambardella, C., Ed.; La Scuola di Pitagora Editrice: Naples, Italy, 2015; pp. 1363-1372.

14. De Alba, M. A methodological approach to the study of urban memory: Narratives about Mexico City. Forum Qual. Soc. Res. 2012, 13, 2.

15. Dong, J.; Qi, L. Semantic network method of urban landscape design. Adv. Mater. Res. 2012, 450-451, 1361-1364. [CrossRef]

16. Dong, J.; Zou, G.T. Semantic network method of urban design scheming. Adv. Mater. Res. 2011, 368-373, 3384-3387. [CrossRef]

17. Lancia, F. The Logic of T-LAB Tools Explained. 2012. Available online: http://www.tlab.it/en/ toolsexplained.php (accessed on 14 November 2015).

18. Lancia, F. T-LAB 9.1-User Manual. 2014. Available online: http://www.tlab.it/en/download.php (accessed on 14 November 2015).

19. China's Urbanization Plan 2014-2020. Available online: http://news.xinhuanet.com/english/china/201403/17/c_133192830.htm (accessed on 15 June 2016). 
20. Verdini, G. The New Urbanisation Plan (2014-2020) and the challenge for the urban governance regime of Midland China. In Urban Futures-Squaring Circles: Europe, China and the World in 2050, Proceedings of the International Conference, Lisbon, Portugal, 10-11 October 2014; Bina, O., Balula, L., Ricci, A., Eds.; Institute of Social Science of the University of Lisbon and Calouste Gulbenkian Foundation: Lisbon, Portugal, 2014 ; p. 88.

21. China's 13th Five-Years Plan (2016-2020). Available online: http://news.xinhuanet.com/english/photo/ 2015-11/04/c_134783513.htm (accessed on 15 June 2016).

22. Du, D.; Huang, L. Urbanisation in China: Regional Development and Co-operation among Cities. UrbaChina Working Paper No. 3. 2014. Available online: https://hal.archives-ouvertes.fr/hal-01023259/document (accessed on 15 June 2016).

23. Elosua, M.; Gipouloux, F.; Goulard, S.; Li, S.; Ni, P. Urbanization in China: The Impact of the Tax-Sharing System and the Definitions of New Strategies. UrbaChina Working Paper No. 1. 2013. Available online: https:/ / hal.archives-ouvertes.fr/hal-00903218v1/document (accessed on 15 June 2016).

24. EU's Rural Development Policy 2014-2020. Available online: http://ec.europa.eu/agriculture/ruraldevelopment-2014-2020/index_en.htm (accessed on 15 June 2016).

25. 2030 Agenda for Sustainable Development, United Nations Sustainable Development Summit, Sustainable Development Goals (SDGs). 2015. Available online: https://sustainabledevelopment.un.org/post2015/ transformingourworld (accessed on 15 June 2016).

26. Lancia, F. The Politics of Climate Change (Anthony Giddens). 2014. Available online: http://tlab.it/en/ allegati/esempi/Giddens_Climate.htm (accessed on 23 August 2016).

27. Börner, K.; Polley, D.E. Visual Insights: A Practical Guide to Making Sense of Data; MIT Press: Cambridge, MA, USA, 2014; pp. 235-266.

28. Fayyad, U.; Piatetsky-Shapiro, G.; Smyth, P. From data mining to knowledge discovery: An overview. In Advances in Knowledge Discovery and Data Mining; Fayyad, U., Piatetsky-Shapiro, G., Smyth, P., Uthurusamy, R., Eds.; American Association for Artificial Intelligence: Menlo Park, CA, USA, 1996; pp. 37-58.

29. Murgante, B.; Borruso, G.; Lapucci, A. Geocomputation and urban planning. In Geocomputation and Urban Planning Studies in Computational Intelligence; Murgante, B., Borruso, G., Lapucci, A., Eds.; Springer: Berlin, Germany, 2009; Volume 176, pp. 1-18.

30. Groat, L.; Wang, D. Architectural Research Methods, 2nd ed.; John Wiley \& Sons: Hoboken, NJ, USA, 2013; pp. 349-377.

31. Massachusetts Institute of Technology Department of Urban Studies and Planning Studio. Sustainable Neighborhoods through Inclusiveness, Connection \& Environment; MIT \& Vanke: Cambridge, MA, USA, 2013; pp. 105-135.

32. Lou, Q. Traditional Architectural Culture of China; China Travel \& Tourism Press: Beijing, China, 2008; pp. 34-45.

33. Snodgrass, A. Architecture, Time and Eternity; Goel, P.K., Ed.; Aditya Prakashan: New Delhi, India, 1990; Volume 2, pp. 366-389.

34. Pitt, A.; Gao, Y. Design of dwellings and interior family space in China: Understanding the history of change and opportunities for improved sustainability practices. Buildings 2013, 4, 823-848. [CrossRef]

35. Donadieu, P. Campagne Urbane. Una Proposta di Paesaggio Della Città; Donzelli Editore: Roma, Italy, 2006.

36. Branzi, A. Modernità Debole e Diffusa. Il Mondo del Progetto All'inizio del XXI Secolo; Skira: Milano, Italy, 2006.

37. Cattaneo, T.; Ni, M. From regeneration of Cascina Triulza to global farm 2.0 a rural urbanism and architecture case study at Milan Expo. Time Archit. 2015, 4, 56-61.

38. Yin, R.K. Case Study Research: Design and Methods, 4th ed.; Sage: Thousand Oaks, CA, USA, 2009; p. 18.

39. Groat, L.; Wang, D. Architectural Research Methods, 2nd ed.; John Wiley \& Sons: Hoboken, NJ, USA, 2013; p. 421.

40. Morello, E.; Piga, B.E.A. Experiential Simulation in Architecture and Urban Space. Ambiances [Online], Experiential Simulation 2016. Available online: http:/ / ambiances.revues.org/671 (accessed on 27 June 2016).

41. De Lotto, R.; Cattaneo, T.; Venco, E.M. Methodology and applications for urban sustainable development. In Proceedings of the 4th International Conference on Energy System, Environment, Entrepreneurship and Innovation (ICESEEI'15), Dubai, United Arab Emirates, 22-24 February 2015.

42. Poerschke, U.; Gampfer, S. Environmentally conscious architecture: Local-global, traditional-innovative, and cultural challenges. Buildings 2013, 3, 766-770. [CrossRef] 
43. Cattaneo, T.; Sandolo, A.; Manzoni, G.D.; Delsante, I.; De Lotto, R.; Bertolino, N. Rural architectural intensification. In Urban Border: 2013 Bi-City Biennale of Urbanism/Architecture (Shenzhen); Jian, Z., Shuang, N., Zhan, Z., Eds.; Tongji University Press: Shanghai, China, 2014; pp. 222-223.

44. Cattaneo, T. (Ed.) Study on Architecture and Urban Spatial Structure in China's Mega-Cities Suburbs; Universitas Studiorum S.r.l. Casa Editrice: Mantova, Italy, 2015.

45. UrbaChina Open Access Working Document Collection. Available online: http://www.urbachina.eu/en/ dissemination/index.html (accessed on 14 February 2016).

46. UrbaChina Final Conference Presentations Held in Paris. 15-16 January 2015. Available online: http: / / urbachina.hypotheses.org/11808 (accessed on 14 February 2016).

47. UrbaChina Policy Briefs. Available online: http://urbachina.hypotheses.org/11668 (accessed on 14 February 2016).

48. UrbaChina Blog. Available online: http://urbachina.hypotheses.org (accessed on 14 February 2016).

49. UrbaChina Photo Collection. Available online: https://medihal.archives-ouvertes.fr/URBACHINA/ (accessed on 14 February 2016).

50. AIM-Bamboo Architecture Design Competition, for the Village of Rural Makers. Available online: https: //www.aim-competition.com (accessed on 4 April 2016).

51. Pavia Municipality City Master-Plan. Available online: http://www.comune.pv.it/site/home/dai-settorie-servizi/settore-pianificazione-e-gestione-del-territorio/pgt---piano-di-governo-del-territorio.html (accessed on 4 April 2016).

(C) 2016 by the authors; licensee MDPI, Basel, Switzerland. This article is an open access article distributed under the terms and conditions of the Creative Commons Attribution (CC-BY) license (http://creativecommons.org/licenses/by/4.0/). 